\title{
La relación entre Matteo Ricci y Diego de Pantoja, misioneros jesuitas
}

\author{
Haitao Peng \\ Universitat Pompeu Fabra
}

\section{Resumen}

Matteo Ricci y Diego de Pantoja fueron los pioneros de la misión de la Compañía de Jesús en China. Ambos trabajaron en la capital de imperio China para evangelizar la doctrina católica desde I6oI. Sin embargo, Ricci y Pantoja no actuaron conjuntamente ni pretendían dirigir su acción a los mismos grupos sociales. En este texto se presentan las diferencias entre ambos religiosos, que llevaron a Ricci a manifestar un descontento fuerte con Pantoja. Diferencias que durante mucho tiempo se han explicado como un choque de caracteres, pero que, releyendo las fuentes, pueden interpretarse como una concepción distinta del método de la acomodación cultural.

Palabras clave: Matteo Ricci, Diego de Pantoja, China, Compañía de Jesús, evangelización, acomodación cultural.

\section{La relació entre Matteo Ricci i Diego de Pantoja, missioners jesuïtes}

\section{Resum}

Matteo Ricci i Diego de Pantoja van ser els pioners de la missió de la Companyia de Jesús a la Xina. Tots dos van treballar a la capital d'imperi Xina per evangelitzar la doctrina catòlica des de I6or. No obstant això, Ricci i Pantoja no van actuar conjuntament ni pretenien dirigir la seva acció als mateixos grups socials. En aquest text es presenten les diferències entre tots dos religiosos, que van portar Ricci a manifestar un fort descontentament amb Pantoja. 
Diferències que durant molt de temps s'han explicat com un xoc de caràcters, però que, rellegint les fonts, es poden interpretar com una concepció diferent del mètode de l'acomodació cultural.

Paraules clau: Matteo Ricci, Diego de Pantoja, Xina, Companyia de Jesús, evangelització, acomodació cultural.

The relationship between Matteo Ricci and Diego de Pantoja, Jesuit missionaries

\section{Abstract}

Matteo Ricci and Diego de Pantoja were the pioneers of the Society of Jesus' mission in China. Both worked in the capital of China to evangelize the Catholic doctrine since I6or. However, Ricci and Pantoja did not act together nor pretend to direct their action to the same social groups. In this text we present the differences between the two religious men, which made Ricci show deep discontent to Pantoja. For a long time this has been explained as a clash of personalities but, rereading the sources, it could be interpreted as a different conception of the method of cultural accommodation.

Keywords: Matteo Ricci, Diego de Pantoja, China, Society of Jesus, evangelization, cultural accommodation.

\section{Introducción}

Los jesuitas llegaron a China en I582, con lo que se inició un nuevo proceso de introducción del cristianismo, de intercambios entre las culturas china y europea. Entre todos ellos destacó Matteo Ricci, representante de la política de adaptación y uno de los pioneros en el desarrollo de esta empresa. Ricci es considerado el jesuita que abrió las puertas a la tarea misionera en China. Pero no debemos olvidar que un jesuita español llamado Diego de Pantoja evangelizó en Beijing durante casi dieciséis ańos. Este último, eclipsado por la figura de Ricci, también tiene su historia y su aportación como pionero de la misión china de los jesuitas. 
Diego de Pantoja nació en Valdemoro (Madrid), en I57I, e ingresó en la Compañía de Jesús a los dieciocho años de edad. Animado por Luis de Guzmán, arzobispo de Toledo y su guía espiritual, así como por las hazañas de los misioneros en Asia Oriental, partió a Lisboa para dirigirse a las misiones de Japón. Pero debido a la complicada situación política de este país, tuvo que modificar su plan inicial y partir hacia China. Pantoja encontró a Ricci en Nankín en marzo de I600, momento en el que empezó su misión evangélica en el Reino del Centro.

Todo se inició con el pie derecho, ya que junto a Ricci obtuvieron una audiencia en la Corte imperial Ming, hecho que les permitió conseguir el permiso de residencia en Beijing, un hito de la misión china. Después de esta audiencia, los jesuitas llegaron a ser muy famosos en la capital, hasta el punto de que su presencia tuvo eco entre las elites burocráticas. Desde entonces, y hasta la muerte de Ricci en I6ıo, trabajaron juntos durante diez años en la capital del Imperio chino.

En las páginas siguientes trato de responder a varias preguntas: ¿cómo se desarrolló la relación entre estos dos jesuitas?, ¿cuáles fueron sus métodos evangélicos?, ¿cuáles fueron sus acuerdos y sus divergencias? Un análisis de estos aspectos podría ser útil para una mejor comprensión de la historia de la evangelización jesuita en China.

\section{El descontento de Ricci con Pantoja}

En I606, en una carta dirigida a Claudio Acquaviva, general de la Compañía de Jesús, Ricci describió a Pantoja en los siguientes términos:

Tenemos aquí un compañero, el padre Diego de Pantoja, a quien el padre visitador declaró hace dos años como «digno de la profesión de los cuatro votos», pero se ha comportado mal. Los hermanos jesuitas y los seminaristas de esta misión llegan incluso a opinar que carece de virtud y de 
sensatez, y creo que tiene que sentir vergüenza, puesto que ya ha trabajado junto a mí durante cinco o seis años. ${ }^{\mathrm{I}}$

Como se puede observar, se trata de una crítica muy severa. El profesor Zhangkai, autor del libro Diego de Pantoja y China [庞迪我与中 国], ha analizado las razones del descontento de Ricci. Según él, este derivaba de la diferencia de carácter de ambos. Ricci era un hombre sociable y humilde, con mucha paciencia, mientras que Pantoja era una persona impetuosa y obstinada.

Además, en esta época, la misión china sufrió muchas adversidades y fallecieron los jesuitas Alessandro Valignano y Luis de Guzmán, que eran importantes para Ricci y Pantoja, respectivamente. Por eso, en ese periodo, el pesimismo inundó a estos jesuitas. Según Zhangkai, esto no les permitió resolver sus diferencias de una forma serena. Este autor opina que, debido a sus orígenes, Ricci prefirió trabajar con los jesuitas italianos y portugueses antes que con jesuitas espańoles. Por otra parte, las autoridades coloniales de Filipinas exterminaron a los chinos que vivían en Manila. En China, se indignaron altos funcionarios provinciales e intelectuales. Así, Ricci consideró que la misión china estaba en peligro debido a los vínculos de Pantoja con España.

En resumen, para Zhangkai, el descontento de Ricci con Pantoja se explica por su origen, identidad y mal humor, y no tanto por la calidad de su trabajo en la misión china.

Sin embargo, si analizamos las palabras exactas de la carta de Ricci, podemos advertir que intentó establecer una comparación entre las capacidades respectivas de Gaspar Ferreira, un jesuita portugués, y Diego de Pantoja:

Otro padre está en esta casa, Gaspar Ferreira, que es el nuevo maestro, persona que combina la integridad moral con aptitud y, al mismo tiempo, es muy inteligente. Ha estado dos años aquí, y me ha causado una

I. Matteo Ricci, Piero Corradini y Francesco D'Arelli, Lettere: 1580-I609, Macerata, Quodlibet, 200I, p. 427. 
impresión muy buena. Ha estudiado teología durante tres años, es un humanista y tiene éxito en leer y escribir chino.

No sé si el padre visitador ha decidido sobre el padre Ferreira, a mí me parece que debería pronunciar los cuatro votos. [...] Su virtud y su modestia son tan extraordinarias que pueden compensar su carencia de estudios. Ha aprendido todo lo que debe saber. Destaca sobre todo su consagración a la labor evangélica en esta zona. Razón por la cual es digno de la profesión de los cuatro votos.

Tenemos aquí a un compañero, el padre Diego de Pantoja, a quien el padre visitador declaró hace dos años «digno de la profesión de los cuatro votos", que se ha comportado mal. Los hermanos jesuitas y los seminaristas de esta misión llegan incluso a opinar que carece de virtud y de sensatez, y creo que tiene que sentir vergüenza, puesto que ya ha trabajado junto a mí durante cinco o seis ańos. ${ }^{2}$

Es evidente que las palabras de Ricci tienen dos objetivos. En primer lugar, su valoración de Ferreira es muy buena, y lo considera digno de la profesión de los cuatro votos. En segundo lugar, hace una crítica al padre Pantoja con su comparación con el jesuita portugués.

Debido a la situación de la misión china, Ricci debía ser más exigente con sus compañeros. En una carta, el jesuita mencionaba que estaba muy ocupado escribiendo libros chinos y que nadie podía ayudarle:

[...] estoy siempre solo aquí escribiendo y ahora puedo decir que nadie me ayuda en esto, así espero que en el futuro haya un padre con más talento que yo y que le quede mucho tiempo para hacer este trabajo [...], por eso aconsejo a los padres que estudien las letras chinas, porque en gran parte la conversión de China depende de eso. ${ }^{3}$

En una carta del mismo año escrita al padre Costa, también dice:

2. Ricci, Lettere, p. 427.

3. Idem, p. 377. 
[...] cuanto más avanzo en este trabajo, más ocupado estoy y mayor responsabilidad recae sobre mí [...]; bastaría con que hubiera un hombre más capaz que yo. ${ }^{4}$

Cuando los jesuitas llegaron a Beijing y fueron recibidos en audiencia por el emperador, apareció un nuevo reto: las actividades sociales interminables. Muchos letrados querían conocer a los sabios extranjeros y visitar la residencia de los jesuitas. Según la costumbre, estos tenían que devolver las visitas y asistir a los banquetes. Ricci quería aprovechar esta oportunidad para establecer una buena relación con los letrados, pero estas actividades le ocupaban mucho tiempo. Evidentemente, Ricci se sentía muy cansado y desesperado porque sus compañeros no le podían ayudar. En este tiempo, solo había dos jesuitas que acompañaban a Ricci en Beijing: Gaspar de Ferreira y Diego de Pantoja.

El hecho de que Ricci estuviera muy contento con Ferreira, que acababa de llegar a China, indica que se mostraba insatisfecho con el trabajo de Pantoja. Antes de llegar a Beijing, Ricci había redactado muchos libros sobre la moral y la cultura europea, pero en este momento tuvo que escribir más sobre los conocimientos que interesaban más a los letrados. Algunas veces se sentía incapaz de gestionar todos los asuntos de la misión. A pesar de que Ricci tuvo una gran necesidad de ayuda, Pantoja no publicó nada en chino hasta I6I4, cuatro años después la muerte de Ricci.

Así, podemos entender que para el jesuita italiano no solo los resultados del trabajo de Pantoja fueron insatisfactorios, sino también su actitud. De este modo, no comparto la opinión de Zhangkai, en la que afirma que la crítica severa de Ricci fuera causada por el prejuicio del origen y cultura ni por el mal humor entre ambos jesuitas en I606. Creo, por el contrario, que la crítica fue un descargo del descontento acumulado a lo largo de los años.

4. Idem, p. 395 . 
Deberíamos preguntarnos: ¿qué llevó al descontento de Ricci con el trabajo de Pantoja?, ¿qué causó la supuesta ineficacia del trabajo de Pantoja, al menos en opinión de Ricci? Podríamos encontrar las respuestas en las divergencias en sus estrategias de evangelización. Esto se puede explicar a través de tres argumentos. Primero, los dos jesuitas tenían actitudes divergentes hacia los letrados chinos; segundo, tuvieron diferentes opiniones sobre cómo traducir el término «Dios» en chino; tercero, poseían distintas actitudes respecto a los letrados chinos.

\section{Actitudes divergentes hacia los letrados chinos}

Ricci opinaba que la misión china necesitaba el apoyo de los letrados. Pantoja no creía que evangelizar a los letrados chinos fuera la única manera de cristianizar China. Una prueba de ello es su actitud hacia Li Zhizao. Cuando Ricci pasaba mucho tiempo discutiendo problemas de matemáticas con Li Zhizao [李之藻], un letrado chino, Pantoja expresaba su desaprobación. Creía que no merecía la pena invertir tanto tiempo con un pagano que no era monógamo.

Debemos saber que desde que ambos jesuitas llegaron a Beijing, estos se dividieron el trabajo. Ricci se concentró en los letrados, mientras que Pantoja se dedicó a la gente sencilla. En un documento de Ferreira se relata que Pantoja había logrado éxitos en el apostolado en las afueras de Beijing. Un convertido llamado Zhangcai [张寀], del estrato más bajo de la sociedad, fue bautizado por Pantoja. Eso certifica que este último trabajó directamente con la gente sencilla. Por el contrario, Ricci intervino en los eventos sociales de las elites burocráticas. Mantener contactos sociales con los misioneros europeos se convirtió en una moda de las elites de Beijing. La gente sencilla no se atrevía a entrar en casa de los jesuitas. De este modo, Ricci no tuvo oportunidad de predicar a la gente de la calle.

Es posible que la experiencia evangélica de Pantoja afectara a su comprensión de la sociedad china. En su obra Qike [七克] De SeptemVictoriis, un libro sobre los siete pecados capitales, en muchas ocasiones 
resalta la monogamia. Para él, la gente sencilla, monógama, era más propensa a aceptar la doctrina cristiana. En cambio, muchos letrados, como las elites sociales, solían tener concubinas. Quizás por eso Pantoja no confiara en ellos.

\section{Diferentes opiniones sobre cómo traducir el término "Dios»}

Ricci estaba a favor del uso de la expresión Shangdi [上帝], que en las obras clásicas chinas se podía identificar con cierta flexibilidad como el Dios cristiano. Pero había muchos jesuitas que no tenían esa opinión. Por ejemplo, Nicolò Longobardi, el sucesor de Ricci, tenía una idea diferente.

¿Qué pensaba Pantoja al respecto? Cuando Wang Zheng [王徵], un letrado de la provincia Shanxi, le preguntó sobre el uso de Shangdi, Pantoja expresó su duda con estas palabras:

Al principio pensaba que Shangdi era apropiado, aunque más tarde he visto que hay muchos templos y estatuas donde llaman a muchos ídolos Shangdi. Supuse que eran templos de Dios y me alegré mucho. Pero luego descubrí que lo eran de los dioses falsos, como Xuantian Shangdi, etc. Además, creo que tienen conceptos erróneos de que los seres humanos pueden ser equiparables a Dios; por eso finalmente me atreví a dejar de usar Shangdi con el objetivo de evitar una posible blasfemia. ${ }^{5}$

Es evidente que existía una divergencia en la traducción entre Ricci y Pantoja. O, al menos, el jesuita español tuvo dudas en el uso de Shangdi.

5. Mi traducción del fragmento: 初意亦以上帝之号甚当也。比见此中庙 貌甚多, 称上帝者甚伙。余以为上帝之庙貌也。窃喜此中人知敬天矣。乃 徐察之, 则率以人神而谬拟之。如玄天上帝之类, 不可枚举。私又想其混 也，以人侪天，故卒不敢以戥吾陡斯之尊称。

Fuente: 宋伯胤, 王徵. 明泾阳王徵先生年谱. 陕西师范大学出版社, (西安 : 陕西师范大学出版社, Song BoyIn, Wang ZHENG, Mingjingyangwangzhengxianshengnianpu, Xian, Shanxishifandaxuechubanshe, 2004, p. I22. 


\section{Las actitudes que Ricci y Pantoja mantuvieron respecto al confucionismo}

En la comunicación con los letrados, Ricci avanzó un argumento simple y radical: en la antigüedad, los sabios chinos conocían y adoraban al verdadero Dios.

Pero ese conocimiento y la práctica habían sido drásticamente sustituidos por los letrados de épocas posteriores y, sobre todo, por la introducción del budismo en China.

Ricci intentó demostrar, usando la razón natural e invocando la autoridad de textos confucianos, la existencia de un Dios omnipotente, creador del cielo y la tierra, que se llamaba Señor del cielo, Tianzhu, en el discurso de los jesuitas. Este Tianzhu recibía el nombre de Shangdi, o tan solo el cielo, Tian, en los antiguos clásicos. Además, Ricci creyó que las éticas confucianas y católicas eran muy semejantes. Por eso intentó evitar las críticas al confucionismo.

Esta evaluación positiva del confucionismo permitió que algunos letrados aceptaran el cristianismo. Después de hablar con Ricci, Xu Guangqi, un letrado chino y colaborador del jesuita italiano, declaró que el cristianismo podía enriquecer la cultura china por «Buru yifo [补儒易佛]», que significa "complementando el confucionismo y tomando el lugar del budismo». ${ }^{6}$

Podría señalarse que Ricci consideraba que tanto el budismo como el neoconfucionismo eran obstáculos para su evangelización, después de haber sido alterado por el budismo. Esta actitud sobre el budismo y el neoconfucionismo satisfacía los deseos de algunos letrados que propugnaban la reforma del confucionismo. Es decir, el objetivo último de Ricci era cristianizar China. Pero al principio necesitaba el apoyo de los letrados. Por este motivo, hizo todo lo posible para encontrar un terreno común con ellos.

6. Xu GuANGQI, 徐光启, 增订徐文定公集. Vol. 1 (上海: 徐顺兴印刷所), Shanghái, Xushunxingyinshuasuo, 1933, p. 20. 
Los planteamientos de evangelización de Pantoja eran distintos. Quizás no estaba familiarizado con los antiguos clásicos y las ideologías de los eruditos de la dinastía Ming, o tal vez no creyera que los sabios chinos conocieran al verdadero Dios.

En sus libros, a diferencia de Ricci, no se puede encontrar ninguna expresión de respeto por el confucionismo. Pantoja criticó que los letrados chinos se dedicaran a la búsqueda de la virtud, así como que creyeran que esta era la clave para conseguir la paz y la seguridad universales. Pantoja opinaba, asimismo, que los letrados se ocupaban de los asuntos de este mundo, pero que no comprendían la fe trascendente y puramente espiritual.

Por ejemplo, en la obra maestra de Pantoja, Qike [七克], escribió:

El orgullo es un deseo enorme de honor causado por muchas razones. En concreto hay cuatro. En primer lugar, la gente cree que la virtud es parte de ella, no la atribuye a Dios. En segundo lugar, sabe que la virtud y la bondad proceden de Dios, pero también son el resultado de su esfuerzo. En tercer lugar, se vanagloria de lo que no tiene. En cuarto lugar, desdeńa a los demás y se considera intocable. [...] En la Biblia se lee que «el orgullo es la raíz de todos los males».?

Pantoja trató de hacer que los chinos entendieran que no se podía conseguir la virtud quedándose solo en la esfera personal, sino que se debía conocer la existencia de Dios. Pantoja señalaba que la cultura china carecía del conocimiento del mundo espiritual. Resulta evidente la diferencia principal entre Ricci y Pantoja: Ricci siempre intentaba identificarse con los letrados para establecer canales de diálogo; en cambio, Pantoja destacaba las diferencias culturales y no evitaba criti-

7. Mi traducción del fragmento: 傲者, 过分之荣愿也。其端甚多。综统 有四。以为善从己出。不归天主。一。知善。从天主出。而因己功。二。 伐有所实无。三。轻人自以为异于众人。四。自满自用。自骋自夸。…... 天主圣经云。一傲之子万罪宗。蓄之者, 必满其祸灾。

Fuente: 庞迪我, 七克 (上海: 上海土山湾印书馆, Diego de Pantoja, De Septem Victoriiis, Shanghaitushanwanyinshuguan, Shanghái, p. I. 
car el confucionismo. El método evangélico de Pantoja causó muchos conflictos con los letrados.

En un prefacio del Qike, un letrado escribió:

El señor Pang (Pantoja), aunque ha mantenido contacto con los chinos, ha perdido muchas veces la oportunidad de hacerse su amigo. Dado que conoce el carácter de los chinos, no le conviene poner todo en evidencia ni tratar los asuntos sin tapujos. ${ }^{8}$

Esta es la razón de las divergencias entre Ricci y Pantoja. Puede que también este sea el motivo por el que la reputación de Matteo Ricci es prominente y durante mucho tiempo la de Diego de Pantoja fue olvidada por la gente.

8. Mi traducción del fragmento: 庞君虽与华人之处, 往往交臂而失, 即 谙华性, 不应彻见腑肝, 穷悉底蕴, 言言当也。

Fuente: Pantoja, De Septem Victoriis, p. 5. 